\title{
Temas científicos en los cinco primeros Simposios Nacionales de Predicción del INM
}

https://doi.org/10.31978/639-19-010-0.769

\author{
Alejandro Roa Alonso' (aroaa@aemet.es) \\ ${ }^{1}$ AEMET / Dirección de Producción e Infraestructuras / Área de Técnicas y Aplicaciones de Predicción
}

\begin{abstract}
RESUMEN
Los primeros cinco Simposios de Predicción del entonces Instituto Nacional de Meteorología (INM), actualmente Agencia Estatal de Meteorología, se celebraron entre los años 1989 y 2001, es decir, entre hace casi veinte y treinta años. Fue una época de gran desarrollo del INM en todos los aspectos, tras el Plan de Renovación Tecnológica de los años 80 y la creación del Sistema Nacional de Predicción.

El Plan de Renovación Tecnológica implicó la instalación de un moderno sistema de recepción de satélites, el desarrollo de una red de radares meteorológicos y otra de estaciones automáticas, el despliegue de una red de detección de rayos, la adquisición de un superordenador para la explotación de modelos de predicción numérica y la implantación de una herramienta informática capaz de integrar de modo eficaz y operativo las informaciones provenientes de todos estos sistemas, que fue el sistema McIDAS desarrollado en el Centro de Ciencia e Ingeniería Espacial (SSEC) de la Universidad de Wisconsin, sistema que sigue funcionando en la actualidad.

En cuanto al Sistema Nacional de Predicción, implicó la creación de los Grupos de Predicción y Vigilancia, lo que además de una regionalización efectiva suponía la ampliación de la atención a muchos más usuarios que los tradicionales aeronáuticos y marítimos.
\end{abstract}

PALABRAS CLAVE: simposios; INM; renovación tecnológica; grupos de predicción y vigilancia; modelización.

\section{INTRODUCCIÓN}

Entre los años 1989 y 2001 el entonces Instituto Nacional de Meteorología celebró en la sede de sus servicios centrales cinco Simposios de Predictores (el primero) o de Predicción (los cuatro siguientes), en las siguientes fechas:

- ¿Noviembre? 1989: Primer Simposio Nacional de Predictores del INM

- Noviembre 1990: Segundo Simposio Nacional de Predicción del INM

- ¿Diciembre? 1992: Tercer Simposio Nacional de Predicción del INM

- 1996: Cuarto Simposio Nacional de Predicción del INM (Memorial Alfonso Ascaso)

- Noviembre 2001: Quinto Simposio Nacional de Predicción del INM

El contexto en el que se celebraron dichos Simposios está descrito en la comunicación presentada por el autor de este artículo y Miguel Ángel García Couto en las XXXV Jornadas de la Asociación Meteorológica Española (RoA y GARCía, 2018). Esta descripción consiste a su vez en unos párrafos extractados del artículo «La evolución de la predicción meteorológica en el Instituto Nacional de Meteorología», de Ángel Rivera, 
Fermín Elizaga y Antonio Mestre, que forma parte de la publicación «El Instituto Nacional de Meteorología: Un reto tecnológico» (RIVERA et al., 2004), y que resumen los principales aspectos de la transformación experimentada por el INM en los años 80 y principios de los 90 , tanto a nivel tecnológico como organizativo.

— «En primer lugar se acometió un Plan de Renovación Tecnológica, para el cual se encargó a un grupo de jóvenes meteorólogos que estudiaran los nuevos desarrollos tecnológicos, especialmente en materia de teledetección, así como las nuevas técnicas de predicción y vigilancia a corto y muy corto plazo. Para ello se visitaron diversos Servicios Meteorológicos de Europa y el de Estados Unidos. A partir de todo ello se diseñó el Sistema Integral de Vigilancia Meteorológica (SIVIM).

En octubre de 1982, cuando ya estaba diseñado en lo esencial el SIVIM, tuvieron lugar las trágicas inundaciones provocadas por la presa de Tous. El recién nombrado gobierno socialista tomó conciencia de inmediato de la necesidad de profundizar en la vigilancia y predicción de las lluvias intensas y dotó al INM de los fondos necesarios para sacar adelante el proyecto SIVIM.

El proyecto SIVIM implicó la instalación de un moderno sistema de recepción de satélites, el desarrollo de una red de radares meteorológicos y otra de estaciones automáticas, el despliegue de una red de detección de rayos y la adquisición de un superordenador para la explotación de modelos de predicción numérica. Además de lo anterior, se buscó una herramienta informática capaz de integrar de un modo eficaz y operativo las informaciones provenientes de todos estos sistemas. Dicha herramienta fue el sistema McIDAS, desarrollado en el Centro de Ciencia e Ingeniería Espacial (SSEC) de la Universidad de Wisconsin. Sistema que sigue funcionando en la actualidad.

Además de lo anterior, se procedió durante esta época a la creación del Sistema Nacional de Predicción. En su concepción se pretendía, además de una regionalización efectiva, la ampliación de la atención a muchos más usuarios que los tradicionales aeronáuticos y marítimos. Se crearon los Grupos de Predicción y Vigilancia (GPV), comenzando en 1986 por el de Palma de Mallorca y finalizando con los de Valladolid y Las Palmas en 1992, aunque posteriormente la predicción de Madrid y Castilla-La Mancha, que se hacía en el Centro Nacional de Predicción, se pasó al Centro Territorial de Madrid, creándose el undécimo y último GPV.

De este modo, a principios de los años 90 el Sistema Nacional de Predicción comenzaba a funcionar operativamente. Se creó un Área de Predicción que coordinaba todo el Sistema y de la que dependían el Servicio Nacional de Predicción, el Servicio de Técnicas de Análisis y Predicción y el Servicio de Predicción Numérica.

En esa época se pusieron en marcha los planes PREVIMET (Predicción y Vigilancia Meteorológica), antecesores del actual Plan Meteoalerta, primero el PREVIMET Mediterráneo, en 1987, luego el PREVIMET Galernas, en 1988, y por último el PREVIMET Nevadas, en 1992.»

Durante la mayor parte de los años correspondientes a la descrita renovación tecnológica y organizativa fue Director de la institución Manuel Bautista. A su vez, el principal promotor de la celebración de los Simposios fue el Subdirector de Predicción y Vigilancia, Alfonso Ascaso, a cuya memoria, pues falleció prematuramente, se dedicó el Cuarto Simposio.

\section{EL PRIMER SIMPOSIO NACIONAL DE PREDICTORES}

El Primer Simposio Nacional de Predictores (aún no «de Predicción») se celebró a finales de 1989, probablemente en el mes de noviembre, aunque no hay constancia fidedigna de la fecha exacta (figura 1). Es decir, se celebró cuando el Plan de Renovación Tecnológica ya estaba en marcha, por lo que su reflejo pudo apreciarse en algunas de las 26 ponencias presentadas, todas ellas por parte del personal del INM, y divididas en tres sesiones: «Estudios sinópticos y mesoescálicos», «Modelos y métodos numéricos» y «Técnicas y métodos operativos». 


\subsection{Sesión 1. Estudios sinópticos y mesoescálicos}

Dentro de esta primera sesión, además del uso del término «mesoescálico» en vez de «mesoescalar», que es el que definitivamente se impuso tras las vacilaciones iniciales, se pueden destacar los siguientes aspectos:

- Mención a las campañas PREVIMET Mediterráneo 1987 y 1988 y a PREVIMET Galernas 1988. Junto con PREVIMET Nevadas, activo en 1992, constituyeron los Planes de PREdicción y VIgilancia METeorológica, PREVIMET, antecesores del actual Plan METEOALERTA.

- Menciones a los Grupos de Predicción y Vigilancia (GPV), entonces en proceso de implantación, así como al Servicio de Técnicas de Análisis y Predicción (STAP), creado poco antes.

- Referencias al Proyecto de Intensificación de la Precipitación (PIP) y al Proyecto ALPine Experiment (ALPEX), como colaboración del INM con otros países. El PIP se desarrolló entre 1979 y 1980 en Valladolid y el ALPEX durante los años 80 .

- Referencias al Sistema Integral de Vigilancia Meteorológica (SIVIM), en fase de implantación. En esta fecha solo estaban disponibles las imágenes de satélite Meteosat (Primera Generación) y TIROS-NOAA, empleadas, entre otras cosas, en

\section{Primier Simiposio NACIONAL DE}
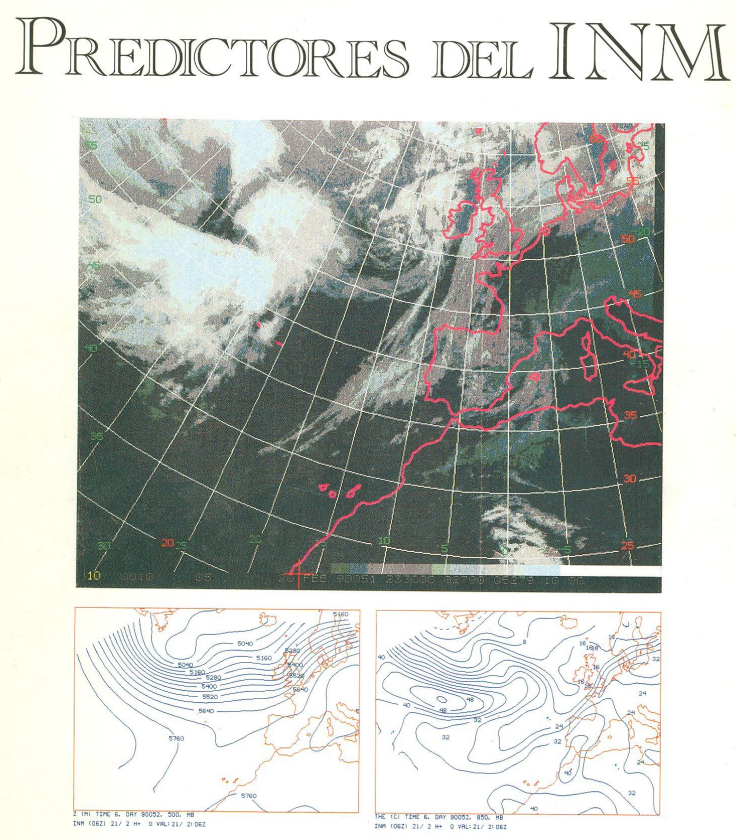

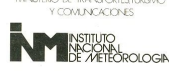

Figura 1. Portada de la publicación de los trabajos del Primer Simposio. el estudio de los Sistemas Convectivos de Mesoescala (SCM).

- Referencias a la importancia de las circulaciones subtropicales y a la ciclogénesis mediterránea.

- Menciones a las inundaciones de Valencia (1982) y País Vasco (1983), que dieron lugar a la potenciación del INM con el primer gobierno socialista.

\section{2. Sesión 2. Modelos y métodos numéricos}

Dentro de esta segunda sesión destacamos lo siguiente:

- Se hizo un repaso de anteriores intentos de implementar la predicción numérica en el SMN (antecesor del INM y AEMET) a fines de los 60 (modelo barotrópico de Von Isacksen) y en el INM a finales de los 70 (modelo de predicción de tres niveles, con hipótesis cuasigeostrófica y análisis objetivo basado en la interpolación óptima).

- Se trató sobre el montaje de la cadena L.A.M. (Limited Area Model), modelo de área limitada que el ECMWF suministraba a los países miembros. Sus características eran:

$>$ Resolución de $0,91^{\circ}$ (aproximadamente $100 \mathrm{~km}$ ). El modelo del ECMWF tenía entonces unos $200 \mathrm{~km}$ de resolución. En ALPEX se experimentó con $0,455^{\circ}$.

$>10$ niveles de presión standard y sin campos de superficie.

$>$ Dinámica del modelo del ECMWF con 15 niveles $\sigma$.

Análisis de interpolación óptima estadística del SMHI (Servicio Meteorológico e Hidrológico de Suecia).

Sin ciclo diurno por no estar parametrizada la radiación. 
- Se mencionó el nuevo ordenador Fujitsu M-382, lo último en computación en aquellos momentos.

- Se trató de los Parámetros de Interés Aeronáutico (PAM) a partir del LAM.

\section{3. Sesión 3. Técnicas y modelos operativos}

De esta tercera sesión, la más breve, pues todavía el desarrollo de técnicas para la predicción operativa estaba en sus inicios, consideramos relevantes los siguientes aspectos:

- Las referencias a los Grupos de Predicción y Vigilancia (GPV), que se acababan de crear, aunque aún faltaba alguno, y que se buscaba potenciar, dentro de un proceso de descentralización de la predicción.

- Referencias a las campañas PREVIMET, como en la primera sesión.

- Menciones a las nuevas fuentes de datos integradas en el SIVIM, ya operativas o bien en desarrollo:

Satélites Meteosat y TIROS-NOAA.

$>$ Estaciones automáticas.

- Radares y red de descargas eléctricas (propuestas para un futuro próximo).

- Mención de las novedosas estaciones WEFAX para transmisión de datos.

- Referencias al uso de SAIDAS/McIDAS, un sistema integral para el tratamiento de información meteorológica que, treinta años más tarde, continúa funcionando de modo operativo en AEMET, y que puede considerarse que sigue siendo imprescindible.

\section{EL SEGUNDO SIMPOSIO NACIONAL DE PREDICCIÓN}

El Segundo Simposio Nacional de Predicción (figura 2) tuvo lugar apenas un año después del primero, entre el 20 y el 22 de noviembre de 1990, y fue casi un calco del anterior. Hubo también tres sesiones, con los mismos títulos que en el Primer Simposio, y un total de 32 ponencias. En cuanto al contenido científico y técnico, destacamos lo siguiente como más relevante:

- Creación de un grupo de trabajo entre el Centro Meteorológico Zonal (CMZ) de Baleares, el Servicio de Predicción Numérica y el STAP, responsables de gran parte de las ponencias.

- Primeros resultados del experimento internacional PYREX, que se estaba realizando en esos momentos, con mucho personal del INM implicado.

- Análisis mesoescalar subjetivo (se consideraba que faltaba mucho para conseguir análisis mesoescalar objetivo). Se presentó el manual de mesoescala de Agustín Jansà.

- Uso de la vorticidad potencial como campo de diagnóstico y pronóstico.

- Continuación de los estudios sobre Sistemas Convectivos de Mesoescala (SCM). Implementación del realce PREVIMET.

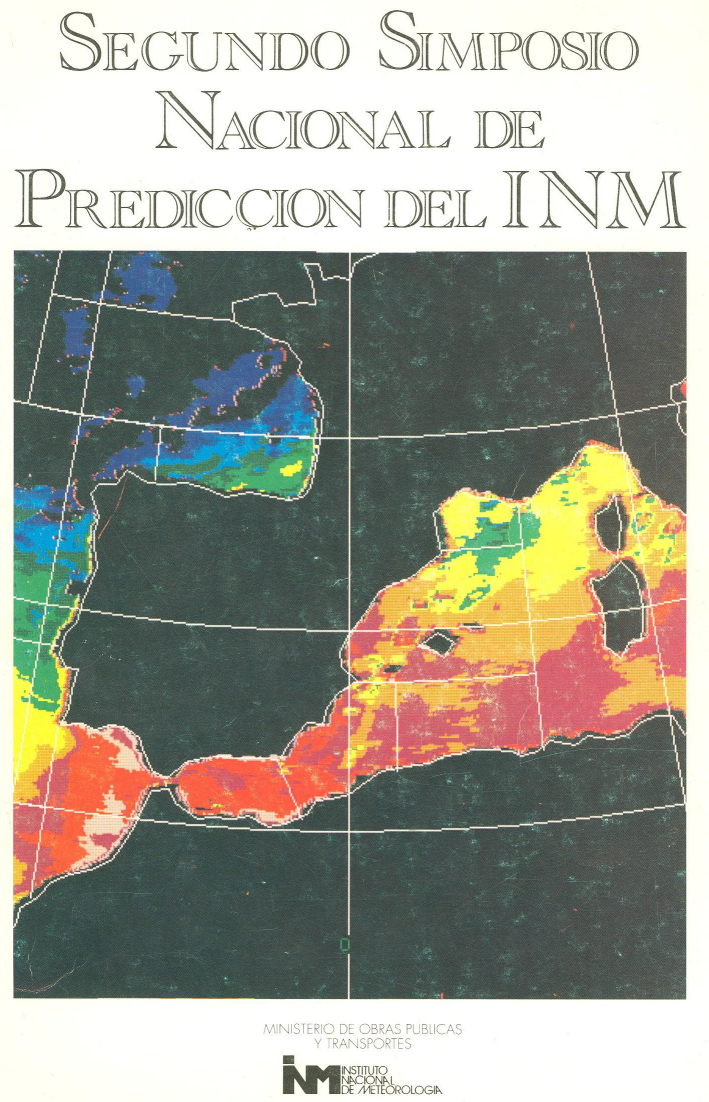

Figura 2. Portada de la publicación de los trabajos del Segundo Simposio. 
- Estudio de vientos a partir de imágenes de satélite en SAIDAS.

- Uso intensivo de SAIDAS/McIDAS.

- Experimentos con el modelo L.A.M. (por ejemplo, sobre la brisa en Mallorca) de resolución 0,455².

- Trabajos preparatorios del apoyo a los Juegos Olímpicos de Barcelona y a la Exposición Universal de Sevilla, que tendrían lugar dos años después.

- Primeras experiencias con el radar meteorológico. Desde inicios de este año estaban operando algunos radares, en banda $\mathrm{C}(5 \mathrm{~cm})$, con barridos cada 10 minutos, 20 exploraciones polares, un barrido Doppler y 12 CAPPI.

\section{EL TERCER SIMPOSIO NACIONAL DE PREDICCIÓN}

Las fechas de celebración del Tercer Simposio Nacional de Predicción (figura 3), aunque de nuevo tampoco hay constancia fidedigna, fueron muy probablemente en diciembre de 1992, dos años después del segundo. En este caso sí hubo algunas innovaciones en la distribución de las 71 ponencias presentadas en distintas sesiones, que fueron cinco, con los siguientes títulos:

- Sesión A: Estudios sinópticos y mesoescalares.

- Sesión B: Modelos numéricos y métodos objetivos.

- Sesión C: Procedimientos operativos de predicción, campañas especiales y verificación.

- Sesión D: Estudios de caracterización de fenómenos meteorológicos.

- Sesión E: PEMMOC/PYREX.

PEMMOC son las siglas del Programa de Estudios Meteorológicos del Mediterráneo Occidental y PYREX fue el Experimento Pirenaico franco-español para el estudio de los efectos de la cordillera pirenaica sobre la circulación atmosférica, que se desarrolló en 1990. En relación con este experimento fueron varios los ponentes ajenos al INM que participaron en el Simposio. Esta apertura a ponentes de fuera del INM se mantuvo y potenció durante las dos siguientes ediciones.

Lo más destacado de este Tercer Simposio, de nuevo de modo muy resumido, fueron los siguientes aspectos:

- «Explosión» de los GPV. Son numerosos los trabajos presentados desde los GPV, especialmente en las sesiones de estudios sinópticos y mesoescalares y en la novedosa de caracterización de fenómenos meteorológicos. Se emplea el radar habitualmente y los fenómenos estudiados abarcan un gran repertorio:

Tormentas, tornados (primeros y tímidos estudios en Galicia) y microbursts.

> Galernas, dipolos y brisas de mar.

$>$ Nevadas, precipitaciones intensas e inundaciones.

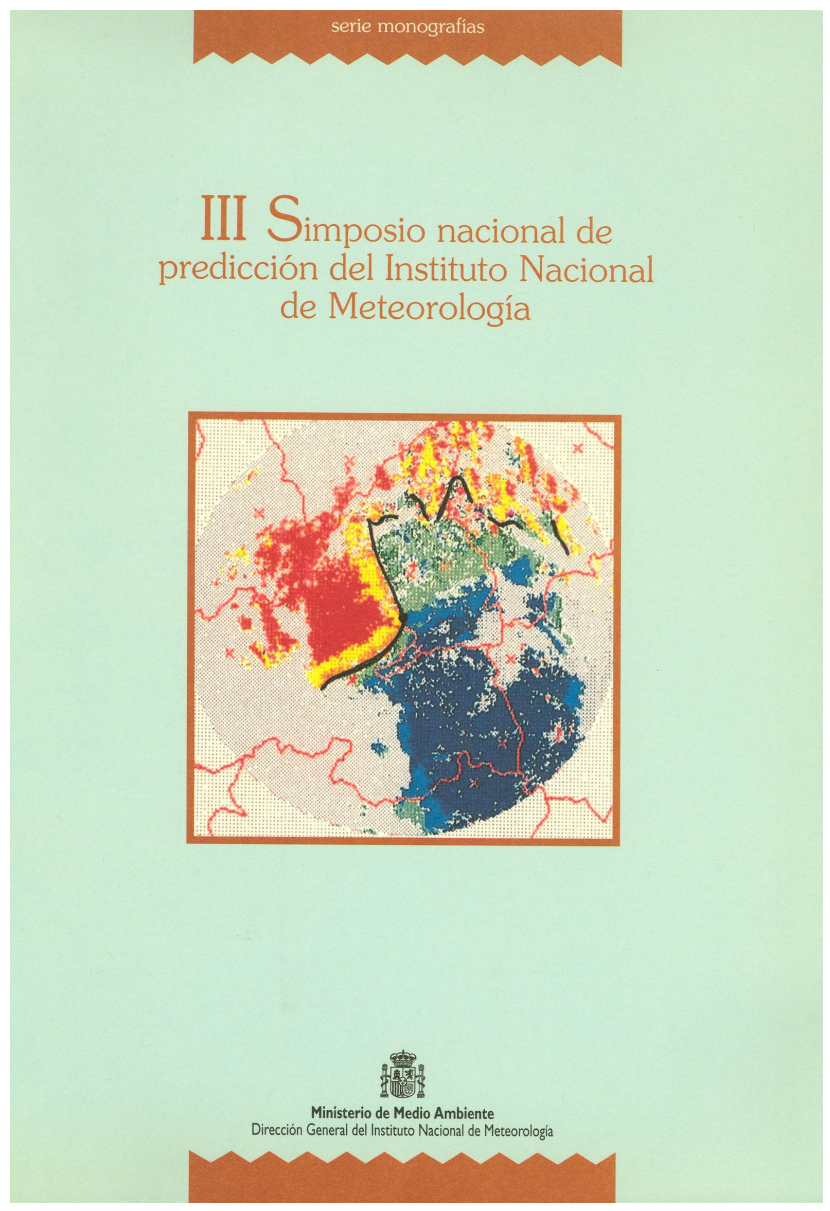

Figura 3. Portada de la publicación de los trabajos del Tercer Simposio. 
- Primer artículo sobre la red de rayos, operativa desde el 28 de enero de 1992.

- Un artículo divulgativo sobre predecibilidad, escrito por Ernesto Rodríguez Camino y José Antonio García-Moya. Poco antes el European Center for the Medium-Range Weather Forecast (ECMWF) acababa de lanzar su Sistema de Predicción por Conjuntos (EPS), por lo que, al menos a nivel operativo, este método era novedoso.

- A falta todavía del desarrollo de los métodos de predicción por conjuntos, en este Simposio se presentaron algunos trabajos sobre los métodos de Montecarlo y de análogos aplicados a la predicción.

- Presentación del programa A. P. O. (Asistencia a la Predicción Operativa), un primer intento de elaborar predicciones en formato texto de modo semiautomático.

\section{EL CUARTO SIMPOSIO NACIONAL DE PREDICCIÓN (MEMORIAL ALFONSO ASCASO)}

El Cuarto Simposio Nacional de Predicción (figura 4) se celebró en fecha indeterminada del año 1996, tras el fallecimiento a finales del año 1995 de Alfonso Ascaso, entonces Subdirector de Predicción y Vigilancia y gran promotor de los Simposios, y a cuya memoria se dedicó este Cuarto.

En esta ocasión el número de ponencias subió hasta 95, divididas en las sesiones siguientes:

- Sesión AI: Estudios sinópticos y mesoescalares: casos de estudio.

- Sesión AII: Estudios sinópticos y mesoescalares: caracterización de fenómenos meteorológicos.

- Sesión B: Técnicas de análisis, diagnosis y predicción.

- Sesión C: Procedimientos operativos de predicción, campañas especiales, verificación y control de calidad.

- Sesión D: Modelos numéricos.

- Sesión P: Pósteres.

Respecto al contenido científico y técnico, resaltamos lo siguiente:

- Estudio de los tornados de Sigüenza del 24 de mayo de 1993 y de L'Espluga de Francolí del 31 de agosto de 1994, además de otros varios en Baleares. Hasta esos estudios existía una idea bastante generalizada, y muy equivocada, de que en España «no había tornados».

- Uso generalizado de modelos conceptuales de mesoescala y de imágenes radar.

- Inicios de la técnica de identificación de células radar en 2D y 3D.

- Uso de las imágenes de vapor de agua para el diagnóstico de niveles altos.

- Redes neuronales para clasificar píxeles de satélite. Clasificación nubosa.

- Comparaciones entre datos de radar y pluviómetro para productos de acumulación.

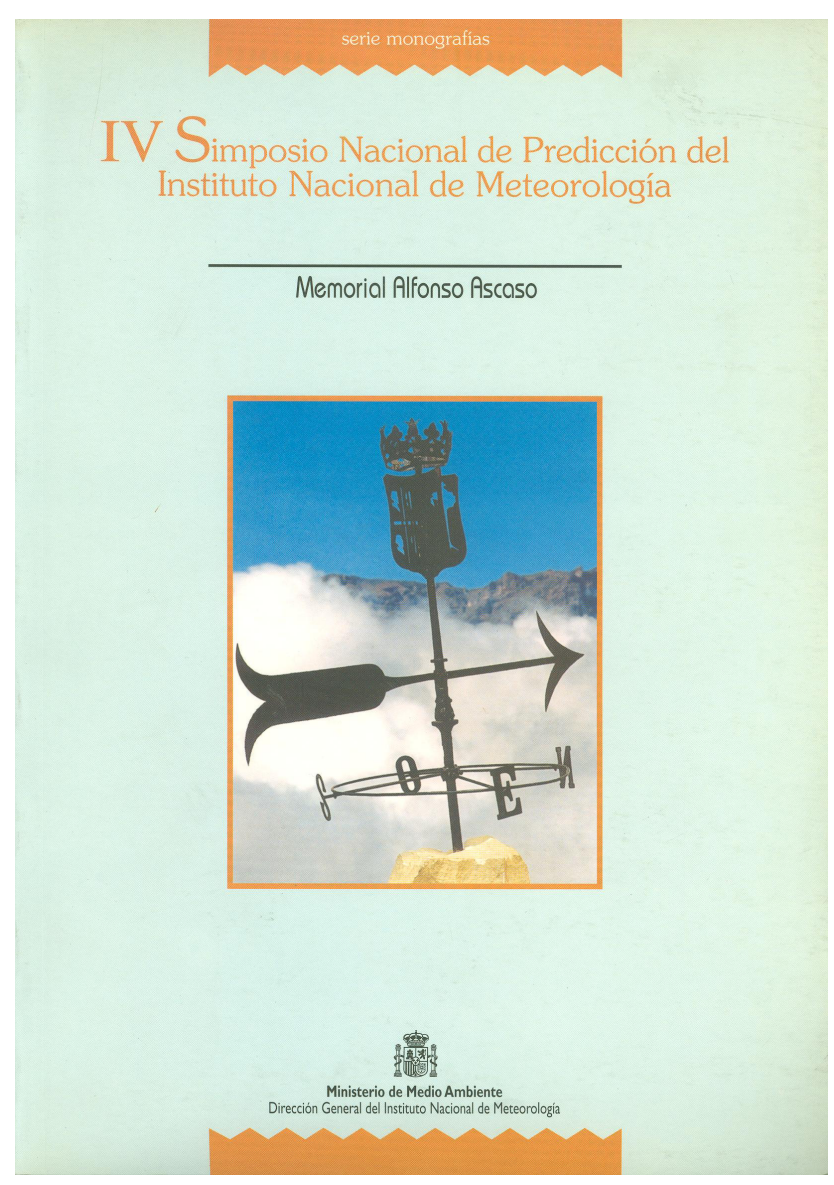

Figura 4. Portada de la publicación de los trabajos del Cuarto Simposio. 
- Estimación de vientos a partir de imágenes de satélite.

- Estudios, por vez primera, de supercélulas.

- Posiblemente, lo más destacado fue la implementación, entonces en curso, del modelo HIRLAM del consorcio del mismo nombre, con coordenada híbrida y 31 niveles, y dos resoluciones, $0,5^{\circ}$ y $0,2^{\circ}$, en el nuevo ordenador vectorial CRAY-C90, un modelo que se ha mantenido en uso durante más de dos décadas.

\section{EL QUINTO SIMPOSIO NACIONAL DE PREDICCIÓN}

Tuvieron que pasar cinco años hasta la celebración del Quinto Simposio Nacional de Predicción (figura 5), celebrado entre el 20 y el 23 de noviembre de 2001. Se presentaron 91 ponencias, divididas en cinco sesiones:

- Sesión A: Casos de estudio.

- Sesión B: Caracterización de fenómenos meteorológicos.

- Sesión C: Técnicas de análisis, diagnosis y predicción.

- Sesión D: Procedimientos operativos de predicción. Verificación.

- Sesión E: Modelos numéricos.

Destacamos, de nuevo de modo somero, los principales y más novedosos aspectos científicos de este Quinto Simposio:

- Lanzamiento operativo del EPS (Sistema de Predicción por Conjuntos) del ECMWF. Ya vimos que en el Tercer Simposio, a finales de 1992, se había presentado un artículo divulgativo al respecto, pero aún tuvieron que pasar varios años para su implementación operativa en el INM.

- Uso por vez primera del término «Ciclogénesis explosiva», en referencia a la situación que produjo

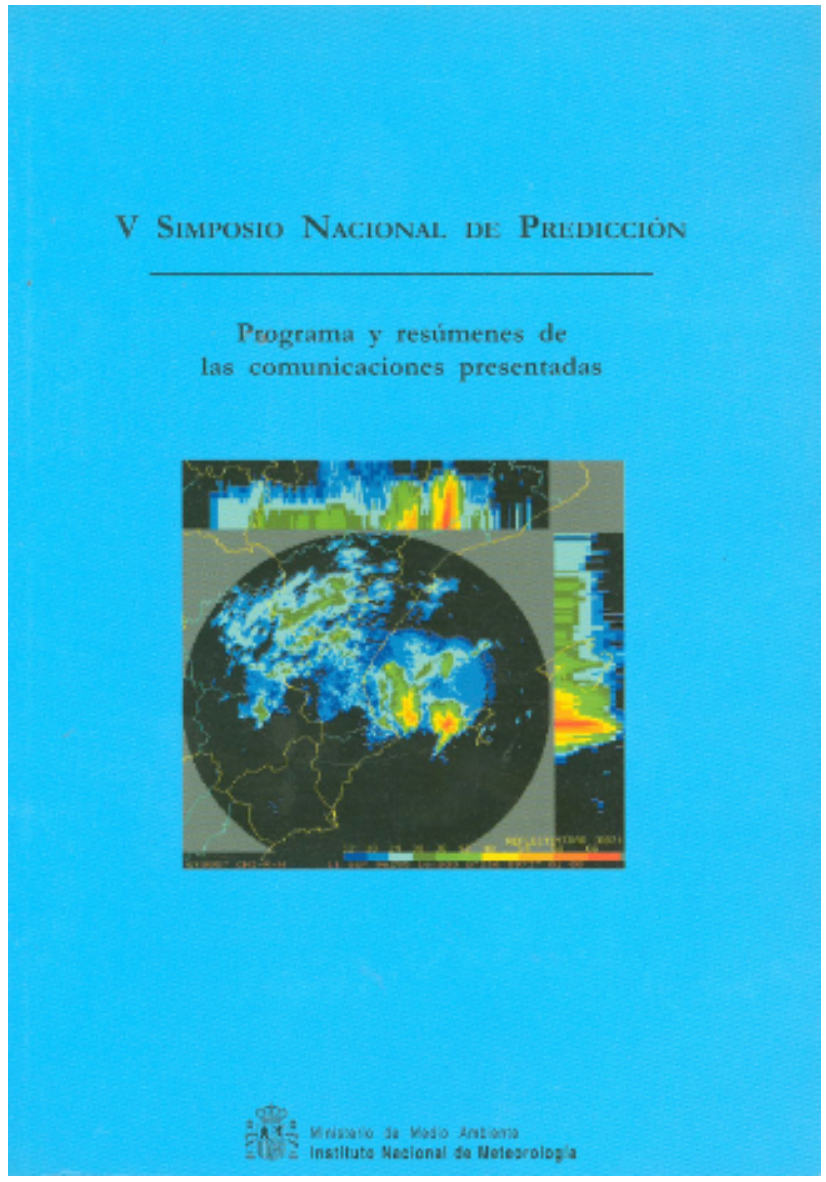

Figura 5. Portada de la publicación de los trabajos del Quinto Simposio. las trágicas inundaciones de Badajoz del 5-6 de noviembre de 1997.

- Primeros productos delNWCSAF deEUMETSAT, para entornos preconvectivos. La red de SAFs (Satellite Application Facilities) se comenzó a definir en 1993, y en 1997 ya estaba creado el de Nowcasting, liderado por el INM-AEMET desde entonces.

- Trabajos sobre predicción analógica (o por análogos) de la precipitación.

- Trabajos sobre predicción estadística por medio de M.O.S. y filtros de Kalman.

- Asimilación 3DVAR en HIRLAM.

- Tímidos inicios de los trabajos en predicción estacional.

- Presentación de Modigraph/Multimeteo, nuevo intento para elaborar predicciones de texto semiautomáticas.

- Presentación de la herramienta de diagnóstico convectivo del STAP.

- Presentación de la herramienta de nowcasting de estructuras convectivas radar 2D y 3D, complementada esta última con un módulo de granizo. 


\section{CONCLUSIONES}

En este breve repaso por la historia de los primeros cinco Simposios de Predicción del antiguo Instituto Nacional de Meteorología se ha hecho un somero catálogo de algunos de los más destacados puntos de interés científico y tecnológico que aparecen en los más de trescientos trabajos presentados en dichos Simposios, y que son un reflejo del estado del arte meteorológico en la década de los noventa del pasado siglo, así como de los esfuerzos empleados en su implementación en el servicio meteorológico español. Queda para un posterior trabajo, forzosamente mucho más amplio, un estudio más detallado de las distintas cuestiones reseñadas en este artículo.

\section{AGRADECIMIENTOS}

El autor agradece a Miguel Ángel García Couto, responsable de publicaciones desde hace muchos años en AEMET y en el antiguo INM, su generosa colaboración en el artículo sobre «Los Simposios de Predicción del antiguo INM» presentado en las Jornadas de la Asociación Meteorológica Española, y citado en las referencias, que ha sido base para la elaboración de este trabajo.

\section{REFERENCIAS}

Instituto Nacional de Meteorología, 1989. Primer Simposio Nacional de Predictores. INM, Madrid.

Instituto Nacional de Meteorología, 1990. Segundo Simposio Nacional de Predicción. INM, Madrid. ISBN 84-7837-060-9.

Instituto Nacional de Meteorología, 1992. Tercer Simposio Nacional de Predicción. INM, Madrid. ISBN 84-498-0233-4.

Instituto Nacional de Meteorología, 1996. Cuarto Simposio Nacional de Predicción. INM, Madrid. ISBN 84-8320-083-X.

Instituto Nacional de Meteorología, 2001. Quinto Simposio Nacional de Predicción. INM, Madrid. ISBN 84-8320-192-5.

Rivera, Á., ElizAga, F. y Mestre, A., 2004. «La evolución de la predicción meteorológica en el Instituto Nacional de Meteorología». En: «El Instituto Nacional de Meteorología: Un reto tecnológico». INM, Madrid. ISBN 84-8320-266-2.

RoA, A. y GarcíA, M. A., 2018. «Los Simposios de Predicción del antiguo INM». XXXV Jornadas Científicas de la Asociación Meteorológica Española. 